\title{
Reestructuración productiva y diferenciación regional. Exportaciones provinciales y desempleo en el Noroeste Argentino (1991-2000)
}

\author{
Sebastián Gómez Lende, Jorge Osvaldo Morina \\ y Guillermo ÁNGEL VelázQuEZ*
}

\section{INTRODUCCIÓN}

En este trabajo nos proponemos estudiar el proceso de diferenciación regional en la Argentina durante la última década, sobre la base de los conceptos de mercado mundial, región y división territorial del trabajo. Nuestra investigación se acota a la región del Noroeste Argentino (NOA), constituida por las provincias de Catamarca, Jujuy, La Rioja, Santiago del Estero, Salta y Tucumán. Esta región se ha desarrollado, en el marco de la división territorial del trabajo reinante desde los albores del modelo agroexportador (1860-1930) hasta la segunda mitad de la década de los ochenta, como un subespacio periférico, ligado a la producción de cultivos industriales destinados al mercado interno, la presencia de algunos segmentos manufactureros beneficiados por los regímenes de promoción industrial vinculados a la producción de bienes de consumo interno (1979-1989), y su condición de área de expulsión demográfica, históricamente proveedora de abundante fuerza de trabajo para el desarrollo de procesos productivos extraregionales.

\footnotetext{
* Sebastián Gómez Lende, Jorge Osvaldo Morina, Guillermo Ángel Velázquez. Centro de Investigación Geográficas. UNG. Argentina
} 
En primer lugar, desarrollaremos una breve aproximación teórica a los conceptos de mercado mundial, división territorial del trabajo y desigualdades regionales. Luego de explicar sucintamente las principales reformas estructurales implementadas en el país durante la década de los noventa, intentaremos comprender las implicaciones fundamentales que los procesos de apertura importadora y reestructuración productiva han poseído sobre la dinámica socioeconómica del NOA. De este modo, procuraremos explicar las elevadas y persistentes tasas de desempleo imperantes en el Noroeste Argentino a través del análisis e interpretación de la estructura productiva regional, desagregada a escala provincial.

La hipótesis que guía el desarrollo de este trabajo señala la existencia de una estrecha relación dialéctica entre el sistemático incremento del desempleo, el surgimiento de nuevas especializaciones productivas exportables, de raigambre primaria, consolidadas por las reformas estructurales de los noventa, y la crisis sufrida por las producciones regionales tradicionales. Sostenemos que esa reorganización productiva de las exportaciones regionales, desencadenada por la nueva división territorial del trabajo, ha tenido una marcada incidencia con respecto a la expulsión de abundantes contingentes de fuerza de trabajo.

\section{MERCADO MUNDIAL, DIVISIÓN TERRITORIAL DEL TRABAJO Y DESIGUALDADES REGIONALES. UNA APROXIMACIÓN TEÓRICO-CONCEPTUAL}

El espacio geográfico es una totalidad, cuyo incesante movimiento de totalización implica su escisión en regiones, es decir, situaciones geográficas concebidas en tanto combinaciones diferenciales de esa totalidad. El grado relativo de prosperidad socio-productiva de las regiones es una variable dependiente de los procesos espacio-temporales que estructuran y reorganizan el espacio geográfico, ligada a los rasgos fundamentales del proceso de acumulación del capital desarrollado a nivel nacional, la dinámica de acumulación del capital imperante a escala mundial, y las características intrínsecas a cada región. Claro está, teniendo en cuenta las formas y los contenidos legados por procesos pretéritos, y los nuevos vectores que participan del proceso contemporáneo de diferenciación regional.

La combinación de tales características, unificadas en un único proceso objetivado diferencialmente en tres escalas (mundo, país y región), engendra una dialéctica mediante la cual se combinan las necesidades de 
cada proceso productivo particular y las demandas del régimen de acumulación que rige, desde los centros mundiales de poder, el devenir de la configuración territorial y la dinámica social de ese país, asegurando de ese modo la reproducción complementaria y coordinada de la división del trabajo. En este contexto, Estado y Mercado desarrollan situaciones de cooperación y conflicto cuya inequívoca consecuencia es la incesante producción de una nueva geografía. La división internacional del trabajo y su correlato interno reorganizan la sociedad y el territorio merced a los intereses de los capitales hegemónicos a escala mundial y las necesidades de las clases dominantes a escala nacional.

La división del trabajo es un rasgo inherente a la economía-mundo capitalista, cuya función estructural es incrementar la productividad del trabajo y el rendimiento del capital. Su configuración espacial varía en cada período histórico, respondiendo a los rasgos propios de cada modo de desarrollo y a los relictos y vestigios de formas, funciones y estructuras heredadas. Imprime así su contenido al espacio geográfico, fragmentando el proceso de trabajo temporal y espacialmente, generando una diferenciación social y territorial sobre la base de una nueva configuración jerárquica de especializaciones productivas y vocaciones exportadoras. Esto significa que "el mundo está organizado en subespacios, articulados por una lógica global" (Santos, 1995: 49).

Los límites de esos subespacios, verdaderos recortes territoriales, son inestables, cambiantes, y esas situaciones geográficas se entrelazan en torno a los vectores de la división territorial del trabajo que participan en su constitución estructural y, al mismo tiempo, de su vaciamiento funcional. La división territorial del trabajo acarrea nuevas formas y mecanismos de diferenciación y desigualdad regional, sustentados en el intercambio y en la circulación de mercancías, plasmados finalmente en la articulación a las estructuras del mercado mundial, alumbrando especializaciones productivas inéditas y engendrando nuevas vocaciones exportadoras.

Cada región es, pues, forma y contenido (véase Sormani, 1977: 170). Un análisis ontológico de las categorías sociales nos revela que la región, desde el punto de vista geográfico, existe objetiva y dinámicamente, en virtud del considerable y variable acervo de condiciones materiales e inmateriales que, engendradas por la división del trabajo, definen su existencia. La región es una totalidad de tercer orden, si consideramos al mundo y al país como un todo, respectivamente, y su existencia se torna concreta merced al devenir de las diversas manifestaciones de los procesos de diferenciación socio-espacial, cuyos mecanismos transforman a cada país en un mosaico 
de subespacios estructurado sobre la base de un cúmulo de desigualdades o asimetrías más o menos durables, interdependientes y acumulativas.

La concentración, centralización e internacionalización del capital "tienden a incrementar las especializaciones regionales al interior de una división del trabajo finamente articulada" (Bradbury, 1985: 43) y, de ese modo, cada región se transforma en un engranaje significativo de la dinámica de acumulación capitalista a escala mundial. Expresado de otro modo, las regiones son el soporte y la condición de una estructura de relaciones globales que, de otra forma, se tornarían irrealizables, y cuyo vehículo geográfico es la división del trabajo.

Esos recortes territoriales se tornan sensibles y mutables frente a las incesantes transformaciones experimentadas por el orden global reinante, adquiriendo, en virtud de las demandas de los capitales hegemónicos, rasgos de rigidez funcional y especificidad productiva. En el período contemporáneo, se construye incesantemente una profusa trama de jerarquías y desigualdades que, merced a la cohesión organizacional engendrada por las condiciones internas y las racionalidades impuestas por el mercado mundial, se tornan fundamentos de las configuraciones regionales de los territorios nacionales.

\section{LAS REFORMAS ESTRUCTURALES DE LOS NOVENTA. APERTURA IMPORTADORA Y REESTRUCTURACIÓN PRODUCTIVA}

Las reformas estructurales implementadas de manera lineal y acrítica durante la década de los noventa han poseído su correlato fundamental en un proceso inédito y simultáneo de desindustrialización de la estructura productiva nacional e inserción regionalmente asimétrica en el mercado mundial. Se trató de un proceso de reestructuración defensiva, derivado de la implantación de un modo de desarrollo de características intensivas, sustentado en un régimen de acumulación de elevada composición de valor del capital, y un modo de regulación que arbitró decididamente en favor de los países e instituciones centrales en la dinámica de acumulación capitalista a escala mundial.

El Estado argentino promovió un proceso sistemático e implacable de reestructuración productiva, sustentado en la producción de bienes no transables de características monopólicas u oligopólicas, y en actividades de sesgo primario, escaso valor añadido, y mermada demanda de fuerza de trabajo. El endeudamiento externo, la apertura comercial y financiera, y la 
convertibilidad monetaria transfirieron a manos de los capitales hegemónicos buena parte de los eslabones productivos más rentables del proceso de acumulación, construyendo los pilares de sustentación de una nueva división territorial del trabajo. De este modo, la Argentina se adhirió una vez más, y con renovada fuerza, a los principios fundamentales del librecambio irradiado por las racionalidades hegemónicas del mercado mundial.

En sólo cinco años, el país se desindustrializó y reprimarizó rápidamente. La combinación de un tipo de cambio convertible y la apertura comercial resultó explosiva para la industria nacional. La desgravación arancelaria y la revaluación cambiaria convalidaron el ingreso masivo de mercancías importadas, impulsando la reestructuración del comercio exterior y la estructura productiva interna. Las industrias nacionales, indefensas ante la remoción de aranceles y el estrangulamiento externo, sufrieron el ahogo del mercado interno y se insertaron con dificultades estructurales en el mercado mundial.

La expulsión de la fuerza de trabajo del proceso productivo y la precarización del mercado laboral, ligada a la subocupación y sobreocupación horaria, la informalidad y la polivalencia, formaron parte de las racionalidades hegemónicas reinantes durante la década de los noventa. El cambio tecnológico, la incorporación masiva de capital fijo y medios de producción, la apertura importadora y la desverticalización de la producción, configuraron una nueva dinámica de acumulación del capital, de sesgo concentrador y excluyente, sustentada en un considerable acervo de innovaciones tendientes a adecuar al tejido industrial nacional y local a los tiempos del mundo. Se consolidó así "un perfil productivo social y territorialmente excluyente" (Morina; Velázquez, 1999: 7), que implica, en consecuencia, la hegemonía del Estado del Malestar (Bustelo, 1992).

Frente a la significativa caída de las importaciones de productos primarios y bienes agroalimentarios, el fuerte incremento de las importaciones de bienes de consumo no durable -industria textil, del calzado, farmacéutica-, y el masivo ingreso de autopartes y bienes de capital, el perfil exportador argentino se concentró en torno a escasos productos primarios y agroindustriales, ciertos bienes intermedios, y automóviles ensamblados con componentes importados.

La apertura comercial generó recesión sobre las pequeñas y medianas empresas, influyendo negativamente sobre los niveles de empleo. El incremento del desempleo y el deterioro de los salarios reales propiciaron que la demanda interna efectiva de bienes industriales con fuerte valor agregado se desplomara, mientras que la primacía del tipo de cambio fijo y sobrevaluado 
determinó el cierre masivo de empresas, con la consiguiente expulsión de fuerza de trabajo. Finalmente, los segmentos y conglomerados exportadores beneficiados por esta dinámica de acumulación, merced a su naturaleza capital-intensiva, absorbieron escasos contingentes de fuerza de trabajo, propiciando el devenir de un proceso de reestructuración productiva articulado a las estructuras del mercado mundial, pero disociado del desarrollo interno del país. Según datos de Sevares (1998), las producciones primarias emplean sólo dos trabajadores por millón de dólares en tanto valor bruto de producción, índice que se halla muy lejos de aquellos que muestran los sectores más afectados por la apertura importadora, es decir, la industria textil $(17,9)$, el calzado $(25,6)$, la maquinaria no eléctrica $(16,4)$ y la maquinaria eléctrica $(15,1)$.

\section{El Noroeste Argentino. Desempleo y estructura PRODUCTIVA EXPORTABLE}

La región del Noroeste Argentino se ha desarrollado, en el marco de la división territorial del trabajo reinante desde los albores del modelo agroexportador (1860-1930) hasta la segunda mitad de la década de 1980, como un subespacio periférico, ligado a la producción de cultivos industriales destinados al mercado interno, la presencia de algunos segmentos manufactureros beneficiados por los regímenes de promoción industrial vinculados a la producción de bienes de consumo interno (1979-1989), y su condición de área de expulsión demográfica, históricamente proveedora de abundante fuerza de trabajo para el desarrollo de procesos productivos extra-regionales.

Desde el apogeo del modelo agroexportador hasta las postrimerías del proceso de industrialización sustitutiva de importaciones, algunas de sus principales actividades productivas -la caña de azúcar tucumana, por ejemplo- han sido protegidas, reguladas y subsidiadas por el Estado. Durante la década de los ochenta, las provincias de La Rioja y Catamarca fueron objeto de la legislación promocional impuesta durante los años del último gobierno de facto (1979 y 1982, respectivamente), propiciando el desarrollo de la industria textil y la producción de electrodomésticos. Finalmente, las reformas estructurales implementadas durante la década de los noventa tuvieron sombrías implicancias para el Noroeste Argentino, imponiendo una severa desarticulación y reorganización de su aparato productivo.

En efecto, las tasas de expulsión de fuerza de trabajo del proceso productivo se incrementaron significativamente durante el período 1991-2000, superando ampliamente su duplicación efectiva. De la exigua cifra levemente 
superior al 6\% registrada en 1991, la región pasó a exhibir, en el año 2000, un contundente 15,4\%. En lo que respecta a su inserción en el mercado mundial, el panorama presume, desde el punto de vista meramente epifenoméni$\mathrm{co}$, alentador. Ostentando, a nivel regional, las tasas anuales de crecimiento exportable más elevadas, luego de la Patagonia, en virtud de la triplicación del desempeño exportador del NOA (1991-1998), la participación del conjunto regional en las exportaciones nacionales resulta, sin embargo, marginal y poco significativa (Gómez Lende, 2003).

Esta región presenta, asimismo, una intensa especialización productiva y una intensa vocación exportadora, desarrolladas en torno a la oferta de bienes con escaso valor agregado, merced al fuerte peso relativo de los segmentos primarios sobre el conjunto. Las ramas agroindustrial y automotriz experimentaron un notable descenso en su participación porcentual relativa sobre el total de las exportaciones regionales, mientras que los sectores de mayor valor agregado (bienes de capital) manifiestan un peso exiguo en su inserción al mercado mundial. Los bienes intermedios, por su parte, ostentan ciertas fluctuaciones y oscilaciones relativas, revelando un significativo estancamiento y una fuerte decadencia, pese a la expansión experimentada, durante la década de los noventa, por la industria de la celulosa y el papel radicada en las provincias de Jujuy y La Rioja.

Pese a la creciente atomización de la oferta exportable regional en torno a las producciones primarias, puede observarse, desde el punto de vista intrasectorial, una notable diversificación interna de los rubros de menor valor agregado. Podríamos citar, entre otros segmentos productivos primarios, a los cultivos industriales (algodón, frutas frescas, caña de azúcar, taba$\mathrm{co}$, etc), la producción de legumbres y hortalizas, la explotación de minerales no metalíferos, metales, piedras preciosas e hidrocarburos, la fundición de hierro y acero, la producción de madera y sus manufacturas derivadas, el cultivo de cereales y oleaginosas, la extracción de sal y yeso, la fabricación de cales y cemento, el desarrollo de productos químicos inorgánicos y la comercialización de animales vivos (hacienda en pie).

Este proceso de reestructuración productiva ha reemplazado a algunos segmentos primarios tradicionales, imponiendo nuevas especializaciones $y$ vocaciones exportadoras. El tabaco, por ejemplo, ocupaba un lugar de relevancia a principios de la década de los noventa, pero luego cayó abruptamente en su participación relativa como consecuencia del descenso de los volúmenes exportados. En efecto, mientras que en 1991 ese cultivo industrial representaba el $31 \%$ de las exportaciones de productos primarios y el 19\% de la inserción internacional del NOA, en 1998 éste detentaba poco 
más del $9 \%$ de las ventas primarias externas y el $5 \%$ de las exportaciones regionales totales. La fibra de algodón, otro de los cultivos industriales tradicionales del NOA, ha sufrido el descenso continuo y sistemático de sus precios internacionales, cayendo ostensiblemente en su participación porcentual relativa sobre el total exportado. La significativa merma en la demanda externa de azúcar, finalmente, ha poseído su correlato en una sistemática disminución de la participación porcentual relativa de dicho producto en las exportaciones regionales. Pese a ello, la caña de azúcar ha representado, durante la última década, el rubro agroindustrial en cuanto a la inserción global del sector en el mercado mundial, concentrando aproximadamente el $35 \%$ de sus ventas externas. Sin embargo, la crisis agroindustrial de la región se traduce en un estancamiento de su desempeño exportador, presentando las tasas de crecimiento exportable más bajas del conjunto, inferiores al $6 \%$ anual.

Las actividades extractivas vinculadas a la explotación y exportación minera, en cambio, han registrado una considerable y acelerada expansión, acicateada por el crecimiento de la minería metalífera y los hidrocarburos. En 1991, las exportaciones minerales totales arrojaban valores levemente superiores al $7 \%$ de las exportaciones de bienes primarios y al $4 \%$ del total regional. En 1999, dichas cifras ascendían al 50\% y 34\%, respectivamente. Si bien la producción de petróleo y gas representan, en cada caso, el $2 \%$ y el $14 \%$ de la producción nacional de hidrocarburos, los minerales metalíferos se han tornado los recursos 'naturales' de la región más codiciados por el mercado mundial. La nueva división territorial del trabajo impone a esta región, de modo inequívoco e implacable, la función de enclave minero, puesto que ésta concentra más del $80 \%$ de la producción nacional de oro, plata y cobre.

De este modo, podemos apreciar el devenir de una crisis sistemática y un progresivo e implacable desplazamiento de las producciones primarias tradicionales (algodón, tabaco, caña de azúcar) en beneficio de la hegemonía detentada por las actividades extractivas ligadas a la comercialización exportable de minerales. En este sentido, se conjugan factores endógenos definidos por el modo de regulación vigente durante la década de los noventa (privatización de empresas vinculadas a la extracción de minerales, concesión de explotación de yacimientos y desregulación de la actividad minera), con factores de índole exógena (caída de los precios internacionales de ciertas materias primas y flujos de inversión extranjera directa hacia yacimientos mineros de la región).

Por otra parte, no existen indicios de un proceso de reconversión agrícola destinado a mitigar las implicancias más nefastas de esos bruscos descensos 
de los precios internacionales de los principales commodities y productos primarios exportados, pese a la histórica y secular importancia que los tabacales, el cultivo e hilado del algodón y la explotación de la caña de azúcar poseen para el empleo de numerosos contingentes de fuerza de trabajo en algunas provincias del Noroeste Argentino. No obstante, las provincias del nordeste, especialmente el Chaco, fuertemente especializadas en la producción de algodón y tabaco, han sufrido de modo más agudo y lacerante que el NOA la crisis y reconversión sistemática de los cultivos industriales.

Paradójicamente, resulta harto significativo el fuerte crecimiento experimentado por las exportaciones industriales de raigambre textil, las cuales ostentan elevadas tasas de crecimiento, superiores al $20 \%$ anual. No obstante, las intensas fluctuaciones apreciadas en cuanto a la exportación de manufacturas textiles y calzado nos permiten revelar en su justa dimensión las severas implicancias que las reformas estructurales de los noventa han acarreado para el sector. La producción de la industria textil en general y, especialmente las ramas manufactureras radicadas en el noroeste, se ha volcado tradicionalmente al mercado interno, especialmente durante las décadas de 1970 y 1980. La apertura importadora, el desempleo generalizado y el brusco descenso del poder adquisitivo de la población han mermado significativamente la demanda efectiva de manufacturas textiles en el país, castigando duramente al sector, el cual ha incrementado sensiblemente su articulación externa. Se trata, pues, de una inserción marginal en la estructura exportable regional, combinada con la imperiosa necesidad de hallar nichos solventes en el mercado mundial que logren mitigar la crisis de este segmento industrial.

Los sectores industriales otrora más dinámicos, como la industria automotriz y los bienes de capital, también han sufrido un severo colapso, tornándose simples vestigios de una división territorial del trabajo pretérita. La industria automotriz, por su parte, ha perdido peso en el total exportado de manera sustancial, pese a haber detentado, a principios de la pasada década, los niveles más elevados del territorio nacional de especialización sectorial, merced a las pujantes terminales tucumanas. La industria de bienes de capital, finalmente, fuertemente subsidiada y protegida durante la década de los ochenta, prácticamente se ha esfumado la estructura productiva regional.

En la reconversión y progresiva desaparición de los rubros industriales más significativos se encuentra, pues, la clave explicativa del incremento exponencial de las tasas de expulsión de la fuerza de trabajo del proceso productivo. Tanto nacional como regionalmente, se ha privilegiado y promovido, durante la década de los noventa, una articulación a las estructuras del 
mercado mundial sustentada prioritariamente en un restringido acervo de especializaciones primarias, provistas de bajo valor agregado y escaso grado de elaboración, y cuyos cuantiosos volúmenes de producción demandan el empleo de escasos contingentes de fuerza de trabajo, generando magros empleos que no mitigan la crisis del mercado de trabajo regional.

Si bien el Noroeste Argentino no se ha caracterizado históricamente por su vocación industrial, la apertura importadora ha afectado de manera negativa el desempeño en el mercado mundial de sus principales manufacturas, configurándolo en tanto un espacio regional aferrado a la exportación de productos de escaso valor agregado, cuyas cotizaciones se encuentran, con la excepción de la minería, en franco descenso y deterioro. Su inserción y participación en el comercio internacional se ha incrementado cuantitativamente durante la pasada década, a costa de consolidar e incrementar sustancialmente una especialización exportable sustentada en la dotación productiva de recursos 'naturales', agudizando la posición periférica del conjunto regional en el territorio nacional.

\section{LAS DESIGUALDADES INTRARREGIONALES. LA DIALÉCTICA ENTRE ESTRUCTURA PRODUCTIVA EXPORTABLE Y DESEMPLEO}

Lejos de ser homogénea, la dinámica de los mercados de trabajo y las estructuras productivas exportables provinciales muestran diferencias significativas objetivadas en el seno del Noroeste Argentino, tanto en lo que respecta a los niveles de expulsión de fuerza de trabajo del proceso productivo como en lo que atañe a la composición cuantitativa y cualitativa de su articulación a las estructuras del mercado mundial. Por tanto, consideramos pertinente y oportuno analizar, interpretar y comparar el comportamiento de estas variables con mayor grado de desagregación espacial.

La provincia de Catamarca, por ejemplo, revela un caso paradigmático de fuerte e intensa reestructuración productiva, plasmada en un abultado crecimiento de sus exportaciones y la presencia de elevados índices de desempleo. Pese a fluctuaciones puntuales, las tasas de desocupación han tendido a incrementarse de manera constante y alarmante, pasando del $9 \%$ en 1991, a casi el $17 \%$ en el 2000 . Sus exportaciones, por otra parte, han experimentado, durante ese período, un crecimiento relativo levemente inferior al $6.000 \%$, exhibiendo una tasa de crecimiento situada en el orden del $50 \%$ anual. En ese contexto, la injerencia de los productos primarios se ha incrementado significativamente. Mientras que en 1991 los segmentos 
de menor valor agregado ya concentraban el $84 \%$ de las exportaciones provinciales, en el año 2000 éstos superaban el $97 \%$ del total. La consolidación de esta vocación exportadora es muy similar a aquella desarrollada por la Patagonia, en la cual algunas provincias -Santa Cruz, por ejemplo-, muestran niveles similares a Catamarca en cuanto a la hegemonía de los bienes primarios exportables.

No obstante, y a diferencia del caso patagónico -ligado a la explotación de hidrocarburos-, Catamarca muestra una intensa especialización productiva exportable sustentada en la minería metalífera, que ha tendido a agudizarse desde la implementación del proyecto "Minera La Alumbrera", de capitales australianos y canadienses, sustentado en la explotación de oro y cobre. Esa explotación minera concentra el $48 \%$ de la inversión extranjera directa (IED) recibida por el NOA durante el cuatrienio 1995-1998 (Argentina, 1999: 63), y ha acicateado bruscamente el brutal incremento del valor de la producción minera provincial, la cual creció casi un $4.000 \%$ durante el trienio 1996-1998. Con el 90\% de la producción nacional de metales preciosos, Catamarca deviene en tanto la primera provincia minera del país, y destina la totalidad del cobre, plata y oro extraídos a la exportación (Andrada, 2002). En 1992, por ejemplo, las exportaciones provinciales de minerales metalíferos representaban tan sólo el $8 \%$ del total exportado a nivel nacional. Siete años más tarde, éstas concentraban el $99 \%$ de las exportaciones mineras nacionales. Durante el cuatrienio 1997-2000, las exportaciones mineras catamarqueñas se sextuplicaron, incrementándose a razón del $88 \%$ anual. De este modo, podemos revelar una jerarquía superior a aquella detentada por la provincia patagónica de Santa Cruz, donde las exportaciones de oro no superan el $10 \%$ del total exportado.

Finalmente, las implicancias respecto del mercado de trabajo no pueden ser más significativas y lacerantes. El desarrollo de la totalidad de las explotaciones mineras del Noroeste Argentino emplea unos 5.200 trabajadores, generando siete puestos de trabajos por cada millón de dólares de valor bruto de producción. Sin embargo, en el caso específico de Catamarca, el emprendimiento minero de mayor envergadura del país -Minera La Alumbrera- emplea a 800 trabajadores permanentes -de los cuales sólo 250 son catamarqueños-, generando 0,45 puestos de trabajo por cada millón de dólares exportado y 0,80 puestos de trabajo por cada millón de dólares invertido. Debemos añadir a este análisis en tanto fenómeno significativo que buena parte de la fuerza de trabajo empleada por los conglomerados transnacionales adjudicatarios de la concesión del yacimiento reconoce un origen extra-provincial, ora provenientes de provincias limítrofes -Tucumán-, 
ora de procedencia extranjera -Canadá, Australia, Estados Unidos y Japón-. Catamarca se configura así, en tanto subespacio periférico, un enclave, en estricto sensu.

El caso de la provincia de Jujuy revela una combinación de variables diferencial con respecto a Catamarca. Si bien sus niveles de desempleo también ascendieron vertiginosamente $-3,3 \%$ en 1991, 19\% en el año 2000 -, sus exportaciones se desplomaron durante ese período, mostrando una tasa de crecimiento situada en el orden del $-0,66 \%$ anual. La participación de los bienes primarios oscila, a lo largo de la década, entre el $70 \%$ y el $80 \%$ del total, mientras que la agroindustria sufre una caída superior al $10 \%$ en su participación relativa, ligada a la crisis azucarera. Los bienes intermedios, plasmados en las exportaciones de papel y cartón, vinculadas, asimismo, a la explotación de la caña de azúcar, también han sufrido un retroceso significativo. En 1991, concentraban el 8\% del total, mientras que el año 2000 esa proporción había descendido al $2 \%$ de las exportaciones provinciales.

Los cultivos industriales, otrora vectores de generación de abundantes empleos, se hallan inmersos en un proceso de crisis y reconversión productiva. Los tabacales, tradicionalmente intensivos en fuerza de trabajo, hoy sólo emplean, en Jujuy y Salta, a 40.000 personas (Andrada, 2002), sucumbiendo frente a la tecnificación agrícola. En las plantaciones, las etapas del proceso productivo que requerían abundantes contingentes de fuerza de trabajo -cosecha y 'encañado'- han sufrido una creciente e incesante mecanización, despojando a un vasto número de trabajadores de sus medios de subsistencia. La apertura importadora le permitió al sector mecanizarse y modernizarse de manera significativa a través de la inversión en capital fijo, fenómeno que se ve reflejado en la duplicación efectiva de los niveles de productividad por hombre ocupado y el alarmante descenso de los salarios reales ajustados por productividad en más de un 70\% (Argentina, 2002). Esas cifras devienen significativas y relevantes si tenemos en cuenta que el tabaco representa aproximadamente el $45 \%$ de las exportaciones jujeñas.

La producción y exportación de caña de azúcar, por su parte, ha sufrido un proceso análogo de reestructuración y mecanización. Cultivo industrial de intensa gravitación en la economía jujeña durante varias décadas, la desregulación del sector -plasmada en la remoción de los programas estatales de créditos y subsidios, que no sólo impedían el ingreso de azúcar importada al mercado interno, sino que también auxiliaban de manera reiterada y sistemática al sector frente a sus recurrentes crisis de sobreproducción, imponiendo preciossostén y estableciendo los precios que los ingenios y acopiadores debían pagar a los cañeros-, y la implacable competencia desatada con respecto a otros 
edulcorantes naturales -el jarabe de maíz de alta fructosa- y sustancias químicas que lo reemplazan en tanto insumo empleado por las industrias de alimentos y bebidas, han condenado a esta vocación histórica de producción regional al ocaso. Asimismo, la inminente apertura de su nicho de mercado frente a la competencia del Brasil -en el marco de la remoción de listas de excepción en el seno del MERCOSUR-, han acelerado la reestructuración sectorial y el proceso de tecnificación del cultivo de caña de azúcar en las provincias especializadas -Jujuy, Salta y Tucumán-, propiciando el advenimiento de un incremento sustancial en la composición de valor y orgánica del capital.

La mecanización de la producción azucarera, en tanto mecanismo de expulsión de fuerza de trabajo del proceso productivo, retroalimenta la crisis del mercado de trabajo, merced a la ausencia de una estructura productiva ligada al imperio de la fabricación de bienes de mayor valor agregado y contenido de progreso técnico, tales como maquinaria eléctrica y no eléctrica, y el desarrollo de manufacturas textiles, impidiendo sistemáticamente la reincorporación del remanente de fuerza de trabajo desempleada. Finalmente, la privatización de la empresa estatal Aceros Zapla, y la fuerte apertura importadora sufrida por el sector siderúrgico han desatado una intensa reestructuración técnica y organizacional implementada por los capitales privados adjudicatarios de los hornos de fundición, tendiente a reducir costos de producción mediante la expulsión sistemática de numerosos contingentes de trabajadores. Frente a la crisis de las industrias demandantes de bienes siderúrgicos, el segmento se ha volcado hacia las estructuras del mercado mundial, representando, no obstante, poco más del $2 \%$ de las exportaciones provinciales. Esa participación marginal muestra una situación bastante similar a la de SOMISA, en la provincia de Buenos Aires, otrora también perteneciente al Estado y que, explotada por el grupo económico nacional Techint a partir de 1993, expulsó al 75\% de su masa laboral.

La provincia de La Rioja revela una situación análoga al caso catamarqueño. Sus niveles de desempleo treparon desde el 5,7\% en 1991 al 12,1\% en el año 2000, y sus exportaciones crecieron aceleradamente, multiplicándose por mil durante el período considerado, exhibiendo una tasa de crecimiento situada en el orden del $26 \%$ anual. Un exhaustivo análisis de la estructura exportable provincial da cuenta de un caso paradigmático y extremo de reprimarización productiva. En 1991, las exportaciones primarias y agroindustriales concentraban el $13 \%$ y el $60 \%$ de las ventas externas provinciales, respectivamente. Sólo un año más tarde, la industria agroalimentaria sólo detentaba un escaso $18 \%$, mientras que la participación de las exportaciones primarias había ascendido a casi el $80 \%$ del total, impulsada 
por el apogeo de la producción en bruto de pieles y cueros, bienes que concentran la mitad de las exportaciones riojanas. En contrapartida, la industria de bienes de capital y la industria automotriz sólo representan, en conjunto, el $2 \%$ del total exportado, lo cual implica que aquellos sectores que poseen una significativa capacidad de generación de empleo merced a su débil composición de valor del capital (es decir, su escasa dotación de capital por hombre ocupado) y sus altos niveles salariales ajustados por productividad (Argentina, 2002), ocupan una posición ínfima y marginal en las exportaciones provinciales.

Ese brutal crecimiento experimentado por la exportación riojana de pieles y cueros ha actuado en desmedro de las industrias peletera y del cuero, privilegiando la inserción en el mercado mundial de una materia prima con escaso grado de elaboración en detrimento de la producción interna de productos con mayor valor agregado y elevada capacidad de generación de puestos de trabajo. Pese a esta realidad, La Rioja presenta tasas de desempleo ostensiblemente menores a aquellas registradas en otras provincias del Noroeste Argentino. Los generosos flujos de recursos financieros destinados por el gobierno nacional para sustentar, durante la década de los noventa, el empleo público provincial, y la consolidación del Régimen de Promoción Industrial riojano, ligado fundamentalmente a la industria textil, y orientado hacia el mercado interno, explican las divergencias del mercado de trabajo provincial con respecto a su correlato catamarqueño. En efecto, las actividades industriales más importantes, plasmadas en la fabricación de textiles y confecciones, calzado y curtido de cueros, papel y cartón, plásticos, maquinaria y equipos, vidrio, medicamentos, perfumería y juguetes, concentran casi el $80 \%$ del valor bruto de producción provincial (Andrada, 2002). Sin embargo, el intenso proceso de reestructuración hacia los eslabones más primarios del proceso productivo impiden una rápida reabsorción de los excedentes de fuerza de trabajo generados, propiciando un débil pero persistente incremento del desempleo.

La provincia de Salta ha incrementado significativamente sus índices de desempleo a lo largo del último decenio. El ritmo de expulsión de fuerza de trabajo del proceso productivo ha ascendido vertiginosamente, si tenemos en cuenta que el desempleo se triplicó entre 1991 (5\%) y el año 2000 (15\%). Las exportaciones provinciales, por su parte, han experimentado un crecimiento superior al $90 \%$, incrementándose a razón de una tasa de crecimiento situada en el orden del $6 \%$ anual. En este contexto, más del $90 \%$ de sus exportaciones corresponden a productos primarios, especialmente cereales, oleaginosas, legumbres, hortalizas, tabaco e hidrocarburos. 
Las exportaciones de combustibles, fundamentalmente petróleo crudo y gas, devienen en tanto vocaciones productivas hegemónicas desarrolladas y consolidadas durante la década de los noventa, merced a la privatización de un considerable acervo de empresas energéticas estatales como Yacimientos Petrolíferos Fiscales, entre otras. Las ventas externas de petróleo y gas concentraban, en el año 2000, más del $40 \%$ de las exportaciones salteñas. Esto significa que casi la mitad de la articulación provincial a las estructuras del mercado mundial se halla atomizada en torno a los hidrocarburos en tanto recursos 'naturales' no renovables, los cuales generan sólo dos puestos de trabajo por millón de dólares de valor bruto de producción, presentan una elevada densidad de capital por trabajador ocupado -merced al incremento de la productividad aparente, superior al $70 \%$-, y cuyos salarios reales ajustados por productividad han experimentado un brusco y constante descenso, superior al 55\% (Argentina, 2002). Con todo, esa jerarquía en cuanto a la explotación y exportación de hidrocarburos es sensiblemente menor a la posición dominante de las provincias patagónicas, en las cuales las ventas externas de combustibles representan el $80 \%$ de las exportaciones totales.

Los cultivos industriales -caña de azúcar y tabaco-, sujetos a una situación de crisis y retroceso a la cual ya se hizo referencia, han experimentando, de modo contradictorio, un significativo incremento de la superficie destinada a su producción, alcanzando unas 20.000 hectáreas (Andrada, 2002). Las exportaciones de oleaginosas, legumbres y hortalizas ( $20 \%$ del total) han experimentado una considerable expansión, merced a la primacía del cultivo de soja transgénica, desarrollado por capitales foráneos. Un fenómeno análogo ha ocurrido con las exportaciones de minerales no metalíferos y rocas de aplicación. En efecto, la explotación provincial de boratos concentra más del $70 \%$ de la producción nacional de ese mineral, destinada en su totalidad al mercado mundial. Las exportaciones automotrices y de bienes de bienes de capital son virtualmente inexistentes.

Finalmente, las cuantiosas inversiones materializadas durante los últimos años nada han podido hacer por reducir los vastos excedentes de fuerza de trabajo, puesto que los segmentos productivos seleccionados por los grandes inversores extranjeros expresan un sesgo particularmente intensivo en capital, especialmente las oleaginosas, el petróleo, el gas y la energía en general, todos ellos objeto de más de dos tercios del total de los montos invertidos entre 1996 y 1999 (Andrada, 2002). Las enormes masas laborales despojadas de sus medios de subsistencia no son absorbidas siquiera parcialmente por esas inversiones, que consolidan a la economía salteña en tanto un enclave agrícola-minero por excelencia. 
Santiago del Estero representa un caso atípico en el esquema regional planteado por el Noroeste Argentino. Sus niveles de desempleo, si bien se han incrementado secularmente durante los últimos años, mantienen cierta distancia de los registros esbozados por las restantes provincias del conjunto regional. Las tasas de desocupación del mercado de trabajo santiagueño, que rondaban el 3,3\% en 1991, alcanzaron el 10,9\% en el año 2000. Las exportaciones provinciales detentan una participación marginal y una escasa jerarquía en el conjunto regional, y se incrementaron, durante el período acotado, a un ritmo situado en el orden del $7 \%$ anual, inferior a Catamarca y La Rioja, pero superior a Salta y Jujuy.

La estructura productiva exportable de Santiago del Estero se encuentra sustentada casi exclusivamente sobre el devenir de los segmentos primarios de la dinámica de acumulación provincial, los cuales, si bien incrementaron, durante la última década, sólo un $6 \%$ su peso relativo sobre el conjunto, representan poco menos de la totalidad de las exportaciones provinciales. En efecto, la comercialización de bienes primarios en sus primeras etapas de elaboración supone más del $90 \%$ de la estructura productiva exportable santiagueña, consolidada fundamentalmente en torno a la producción de cereales, oleaginosas, algodón, legumbres y hortalizas. Las agroindustrias, escasas y poco dinámicas, experimentaron un retroceso brutal, puesto que su participación en las exportaciones provinciales cayó del $10 \%$ en 1991 al $1 \%$ hacia finales de la década de los noventa.

Las industrias del calzado, por su parte, fuertemente estancadas y relegadas, detentan, a excepción de algunos años puntuales, poco más del 1\% del total exportado, truncando de ese modo las posibilidades de expansión del único segmento productivo radicado en la provincia provisto de una importante capacidad de generación de empleo. En contrapartida, la hegemonía del cultivo de oleaginosas -Santiago del Estero es la cuarta provincia productora de soja transgénica- impone cierto marco dicotómico de exclusión social y expansión productiva, puesto que esas explotaciones generan escasos puestos de trabajo.

De manera análoga al caso riojano, el incremento poco significativo de los niveles de desempleo se debe al enorme peso del sector público en cuanto a la generación de puestos de trabajo. A diferencia de otras provincias argentinas, tales como Neuquén, Santa Fe y Mendoza, en las cuales el empleo público mermó sustancialmente, Santiago del Estero se muestra en tanto una de las provincias del interior del país menos permeable a la racionalidad hegemónica imperante durante la década de los noventa, plasmada esta última en la reducción secular de la plantilla laboral con la que contaba 
el Estado nacional y sus correlatos provinciales, en virtud de las privatizaciones y la desregulación. Más allá del debate acerca del carácter genuino de estos puestos de trabajo y el sesgo clientelístico adoptado en su generación, resulta rotunda e inequívoca la responsabilidad de esa variable en tanto mecanismo de mitigación de la crisis del mercado de trabajo provincial, merced al papel parcial de la administración pública como empleadora de los excedentes de fuerza de trabajo rechazados por el sector privado. Esta situación geográfica -exportaciones escasas, hegemonía del sector primario, crecimiento lento y poco significativo del desempleo, papel importante del Estado provincial en tanto empleador- se asemeja, en muchos aspectos, al caso de Formosa, en el nordeste argentino.

Asimismo, las fuentes estadísticas empleadas para el desarrollo de esta investigación sólo efectúan explícita referencia a los niveles de expulsión de la fuerza de trabajo acotados exclusivamente al aglomerado urbano relevado, esto es, Santiago del Estero-La Banda, y no a la provincia en su conjunto, revelando una suerte de subregistro que excluye de modo inequívoco y sistemático a aquella PEA que no residen en la ciudad principal, la cual presenta rasgos fuertemente vinculados al desarrollo de actividades sustentadas en la prestación de bienes y servicios de naturaleza no transable y, por ende, no sujetas al comercio internacional. El particular sesgo terciario de la capital santiagueña (más del $66 \%$ del Producto Bruto Geográfico Provincial) y el importante peso del sector público provincial implican menor representatividad de las tasas de desempleo observadas, especialmente si recordamos las características eminentemente extractivas y campesinas de la economía provincial. Este problema de subregistro también resulta significativo en algunas provincias del nordeste, tales como Misiones.

La provincia de Tucumán, finalmente, presenta la situación más grave y penosa del mercado de trabajo regional. Sus índices de desempleo son muy elevados, trepando desde el $11,4 \%$ en 1991 hasta el $18,4 \%$ a finales de la década, sin excluir la cifra cercana al 22\% registrada en el año 1996. Paradójicamente, se configura en la única jurisdicción que, desde un punto de vista meramente epifenoménico, ha logrado mantener relativamente estable su estructura productiva exportable, especializándose incluso en rubros de cierto progreso técnico y mayor valor agregado, como la industria automotriz. En efecto, y a diferencia del resto de las provincias del Noroeste Argentino, las exportaciones de productos primarios representan tan sólo un tercio del total. La economía tucumana posee una agroindustria pujante y detenta una intensa especialización productiva y una fuerte vocación exportadora con respecto a la producción y comercialización de vehículos 
-monopolizada por el conglomerado sueco Scania-, superior incluso a la que presentan provincias históricamente especializadas sectorialmente, como Córdoba, Santa Fe y Buenos Aires, en el marco de la región pampeana. En efecto, la industria automotriz concentra el $20 \%$ de las exportaciones tucumanas.

No obstante, estas cifras enmascaran una realidad muy diferente, puesto que, en virtud del retraso cambiario, la apertura importadora, la desregulación y las nuevas normas del mercado mundial, la "producción metalúrgica tucumana prácticamente desapareció con el cierre de los talleres ferroviarios, la declinación de los ingenios y la falta de integración nacional de Scania" (Mayo, 1995: 25). La participación de la industria textil y los bienes de capital en las exportaciones provinciales, asimismo, es exigua y poco significativa. La provincia de Tucumán también se ha tornado una de las jurisdicciones más golpeadas durante la última década por los embates del proceso de desindustrialización, dado que, entre 1985 y 1994, ésta perdió el 32\% de sus establecimientos industriales (Argentina, 1999: 63).

La apertura sufrida por la industria automotriz también fue significativa, promoviendo y agudizando la importación de autopartes y componentes otrora de fabricación nacional. Si bien esa especialización productiva deviene en tanto segmento ligado a la generación de abundantes puestos de trabajo -8,8 empleos por cada millón de dólares de valor bruto de producción-, la situación y jerarquía provincial, merced a las reformas estructurales de los noventa y la división internacional del trabajo impuesta por el grupo sueco, desataron nefastas implicancias con respecto a la dinámica del mercado de trabajo tucumano.

Las plantas automotrices radicadas en la provincia producen camiones para el mercado interno y autopartes -cajas de cambio, diferenciales, palieres y engranajes del motor- para las plantas de Scania localizadas en el Brasil, de las cuales recibe, a su vez, cabinas, motores y ejes, ensamblados en Tucumán. La asimetría cambiaria con el Brasil, destino del $90 \%$ de las exportaciones automotrices tucumanas, y la retracción del mercado interno argentino implicaron la declinación de la capacidad de generación de empleo de esta industria. Algunas líneas de producción trabajan al 50\% de su capacidad, con la consecuente expulsión de fuerza de trabajo, mientras que la productividad aparente de las tareas de ensamblaje experimentó un crecimiento superior al $90 \%$ (Argentina, 2002). Si bien más aguda y lacerante, la crisis de la industria automotriz tucumana se asemeja ciertamente al colapso sufrido por las terminales automotrices bonaerenses, cordobesas y santafesinas. 
Por otra parte, la incesante mecanización y tecnificación de los ingenios azucareros tucumanos, desatada no sólo por la declinación de los volúmenes de la producción azucarera provincial y la competencia que representan edulcorantes y otras sustancias químicas -las cuales acotan significativamente los nichos de mercado del sector, fundamentalmente la demanda interna de la industria de alimentos y bebidas-, sino también merced a la imposición de gravámenes de importación variables para el azúcar, la desregulación sectorial y la inminente apertura frente al MERCOSUR -liberalizando de ese modo la importación de azúcar brasilera, más competitiva-, truncan notablemente la capacidad de generación de empleo del sector, merced a la incorporación e incremento sistemático de la dotación de bienes de capital y otros medios de producción en detrimento de la participación de la fuerza de trabajo en el proceso productivo. La mecanización de la cosecha de los cultivos industriales, en este caso el azúcar, son harto significativos. Según datos de Mayo (1995: 25), "una cosechadora integral es capaz de procesar 600 toneladas por día mientras que un cosechero puede recolectar un promedio diario de 1,5 toneladas", lo cual implica que cada unidad física de capital constante empleada reemplaza o sustituye a unos 400 cosecheros. Puesto que en 1995 comenzaron a funcionar en la provincia unas sesenta cosechadoras de última generación, la producción bruta total de caña de azúcar habría eliminado unos 24.000 puestos de trabajo.

Finalmente, y pese a que las exportaciones de productos primarios representan, en apariencia, tan sólo un tercio de las exportaciones totales, un análisis e interpretación más riguroso desenmascara y revela una situación geográfica muy diferente, sustentada en el monocultivo de cítricos. En efecto, el circuito productivo del limón, plasmado en la exportación de cítricos frescos, productos de origen agroindustrial -limones procesados, jugos- $y$ bienes intermedios -aceites y productos esenciales derivados del procesamiento ulterior de ese cítrico-, concentra el $60 \%$ de las exportaciones tucumanas, transformando a esa provincia en la responsable del $25 \%$ de la producción mundial de limones. Ese cultivo, nacido a comienzos de la década de los noventa, en primera instancia, en tanto una opción agrícola destinada a mitigar la crisis sufrida por la industria azucarera, desarrolló rápidamente una vocación exportadora y se tornó una especialización productiva hegemónica. El limón, al igual que la soja transgénica -otro de los segmentos primarios omnipresentes en las exportaciones tucumanas- se desarrollaron como explotaciones agrícolas intensivas en capital, con escasa capacidad de generación de empleo, que ni siquiera absorben la mitad de la fuerza de trabajo expulsada por la mecanización de los ingenios azucareros. 
En este sentido, pues, la presencia de enormes excedentes de fuerza de trabajo registrados en esta provincia obedece tanto a la creciente reprimarización de las exportaciones tucumanas, merced al surgimiento de nuevas vocaciones exportadoras -limones, soja-, como a la crisis y reestructuración de otros segmentos productivos tradicionales -la industria automotriz, los ingenios azucareros-, los cuales asumen un sesgo particularmente intensivo en capital, con la consecuente merma en la capacidad de generación de empleo.

\section{REFLEXIONES FINALES}

En este trabajo, hemos desarrollado una descripción detallada y una interpretación rigurosa, sobre la base de los conceptos de mercado mundial, desigualdades regionales y división territorial del trabajo, de la profusa trama de nexos relacionales tejida entre la estructura productiva exportable y los elevados índices de desempleo sufridos por el Noroeste Argentino. En efecto, hemos revelado la existencia de una estrecha relación dialéctica entre el incremento sistemático del desempleo, el surgimiento de nuevas especializaciones productivas exportables -de raigambre primaria, consolidadas por las reformas estructurales de los noventa-, y la crisis sufrida por las producciones regionales tradicionales. De este modo, esa reorganización productiva de las exportaciones regionales, desencadenada por la nueva división territorial del trabajo, se ha transformado en uno de los principales mecanismos de modernización regional y exclusión social, provisto de una inequívoca incidencia con respecto a la expulsión de abundantes contingentes de fuerza de trabajo.

En este sentido, la articulación subordinada del país como un todo con respecto a la estructuras del mercado mundial ha descargado buena parte de la crisis nacional en el Noroeste Argentino, merced a la crisis y reestructuración de los tradicionales cultivos industriales -tabaco, algodón, caña de azúcar-, el ocaso de algunas ramas manufactureras -industria textil, automotriz, y el advenimiento y posterior consolidación de nuevas especializaciones productivas y vocaciones exportadoras, tales como oro, plata, cobre, boratos, petróleo, gas, limones y soja transgénica. En efecto, los casos del apogeo de la minería metalífera en Catamarca, la exportación de pieles y cueros en La Rioja, y la explotación de boratos e hidrocarburos en Salta son concluyentes. El agudo proceso de desindustrialización y la crisis del mercado de trabajo regional permiten revelar, asimismo, un sombrío retrato de la sociedad y el territorio del Noroeste Argentino, en virtud de la hegemonía de los 
rubros primarios y / o los segmentos intensivos en capital en la dinámica de acumulación regional, planteando severos interrogantes.

¿Cuál será el futuro inmediato de la estructura productiva exportable y del mercado de trabajo de los casos analizados? ¿Cuáles serán las nuevas vocaciones exportadoras y especializaciones productivas que se concretarán en la sociedad regional ante el agotamiento inexorable de los recursos 'naturales' que, hoy día, dinamizan buena parte del perfil exportador?

En este contexto, el Noroeste Argentino se torna un vasto mosaico de subespacios articulados de manera subordinada y dependiente al mercado mundial, situaciones geográficas de crisis y fragmentación, engendradas merced a las reformas estructurales instrumentadas durante la última década, resultado inseparable de la compleja trama de interdependencias funcionales tejida entre el Estado nacional, sus correlatos provinciales y los capitales hegemónicos. En el plano estrictamente teórico, el análisis e interpretación de los principales rasgos socioeconómicos pertinentes a esa funcionalización regional de la configuración territorial y la dinámica social del país, nos permiten dar cuenta de las modificaciones en la división territorial del trabajo en tanto proceso y, al mismo tiempo, revelar, la naturaleza histórica y, por tanto, mutable, de la región geográfica.

Recibido 03.09.04

Aceptado 01.03.05

\section{BIBLIOGRAFÍA}

ANDRADA, L. "Escenarios provinciales en la coyuntura: panorama de las principales actividades económicas". Provincias seleccionadas: Catamarca, Jujuy, La Rioja, Salta, Santiago del Estero y Tucumán. Serie de Documentos Economía y Producción. Buenos Aires, 2002. Consejo Federal de Inversiones.

Argentina. Anuario Estadístico de la República Argentina. Vols. 9, 14 y 16. Buenos Aires, 1993. Instituto Nacional de Estadística y Censos.

Argentina. Anuario Estadístico de la República Argentina. Vol. 14. Buenos Aires, 1998. Instituto Nacional de Estadística y Censos.

ARGENTINA. "Evolución de las inversiones en las provincias y el nuevo patrón de actividades". En Notas de la Economía Real. Nro. 10. Buenos Aires. Centro de Estudios para la Producción. 1999. Págs. 59-68.

Argentina. Anuario Estadístico de la República Argentina. Vol. 16. Buenos Aires, 2000. Instituto Nacional de Estadística y Censos.

Argentina. Encuesta Permanente de Hogares. Octubre de 2000. Buenos Aires, 2001. Instituto Nacional de Estadística y Censos.

Argentina. Fichas industriales 2002. Buenos Aires, 2002. Ministerio de la Producción.

BRADBURY, J. H. "Regional and industrial restructuring processes in the new international division of labour". En Progress in Human Geography. Nro. 1. Vol. 9. Londres, 1985. Págs. 38-63. 
554 • SEBASTIÁN GÓMEZ LENDE, JORGE OSVALDO MORINA Y GUILLERMO ÁNGEL VELÁZQUEZ

Bustelo, E. "La producción del Estado del Malestar. Ajuste y política social en América Latina". En Cuesta Abajo. Los Nuevos Pobres: Efectos de la Crisis en la Sociedad Argentina. Minujín, A. (Comp). UNICEF / LOSADA. Buenos Aires, 1992. Págs. 119-142.

Consejo Federal De InVERSIONES. Exportaciones provinciales por capítulos 1991-2001. Buenos Aires, 2002. Información Estadística Federal.

GÓMEZ LENDE, S. División espacial del trabajo y desigualdades regionales en la inserción al mercado internacional frente al proceso de apertura importadora y reestructuración productiva en la Argentina (1991-1999). Tesis de Licenciatura. UNCPBA, 2003.

MAYO, A. "Plan Cavallo y economías regionales: el mito de la `salida exportadora". En Realidad Económica. Nro. 135. Buenos Aires, 1995. IADE. Págs. 10-34.

Morina, O; VelÁZQUeZ, G. "Consecuencias socio-ambientales derivadas de la privatización petrolera en Neuquen". Revista Geografia. Vol. 24. Nro. 2. São Paulo, 1999. Págs. 5-21.

Santos, M. Metamorfosis del Espacio Habitado. Barcelona, 1995. Oikos-Tau.

Sevares, J. "Cuando exportar no crea empleo". En Diario Clarín. Buenos Aires, 22 de noviembre de 1998.

SORMANI, H. "Formación Social y Formación Espacial: Hacia una dialéctica de los asentamientos humanos". En Estudios Sociales Centroamericanos. Nro. 17. San José de Costa Rica, 1977. Págs. 147-173.

\section{ANEXo ESTADÍstico}

Cuadro 1. "Porcentaje de desempleo, por provincias". Noroeste Argentino.

PERÍODO 1991-2000

\begin{tabular}{lrrrrrrrrrr} 
Tasa de Desempleo & $\mathbf{1 9 9 1}$ & $\mathbf{1 9 9 2}$ & $\mathbf{1 9 9 3}$ & $\mathbf{1 9 9 4}$ & $\mathbf{1 9 9 5}$ & $\mathbf{1 9 9 6}$ & $\mathbf{1 9 9 7}$ & $\mathbf{1 9 9 8}$ & $\mathbf{1 9 9 9}$ & $\mathbf{2 0 0 0}$ \\
\hline Noroeste Argentino & 6,2 & 7,6 & 8,00 & 10,0 & 13,2 & 14,4 & 12,9 & 10,9 & 13,0 & 15,4 \\
Catamarca & 9,0 & 5,9 & 9,7 & 7,5 & 12,1 & 12,7 & 13,2 & 10,7 & 16,0 & 16,8 \\
Jujuy & 3,3 & 6,6 & 6,5 & 9,7 & 12,4 & 12,5 & 15,5 & 15,6 & 16,1 & 19,1 \\
La Rioja & 5,7 & 8,7 & 5,7 & 10,9 & 11,3 & 10,5 & 9,7 & 7,6 & 7,2 & 12,1 \\
Salta & 4,7 & 9,8 & 10,1 & 13,3 & 15,7 & 16,3 & 14,3 & 12,0 & 14,1 & 14,9 \\
Santiago del Estero & 3,2 & 2,3 & 3,9 & 4,6 & 8,6 & 12,4 & 9,4 & 4,8 & 8,7 & 10,9 \\
Tucumán & 11,4 & 12,5 & 11,8 & 14,2 & 19,1 & 21,8 & 15,5 & 14,9 & 15,9 & 18,4
\end{tabular}

Fuente: Elaboración personal sobre la base de ARGENTINA. (1993); ARGENTINA. (1998); ARGENTINA. (2000); ARGENTINA. (2001).

CuAdro 2. "PARTICIPACIÓN PORCENTUAL EN LAS EXPORTACIONES REGIONALES, POR PROVINCIAS". NOROESTE ARGENTINO. PeríOdo 1991-2000

\begin{tabular}{lrrrrrrrrrr} 
\% Exportaciones & $\mathbf{1 9 9 1}$ & $\mathbf{1 9 9 2}$ & $\mathbf{1 9 9 3}$ & $\mathbf{1 9 9 4}$ & $\mathbf{1 9 9 5}$ & $\mathbf{1 9 9 6}$ & $\mathbf{1 9 9 7}$ & $\mathbf{1 9 9 8}$ & $\mathbf{1 9 9 9}$ & $\mathbf{2 0 0 0}$ \\
\hline Catamarca & 1,44 & 2,03 & 1,73 & 3,64 & 1,70 & 1,83 & 6,94 & 29,39 & 33,52 & 27,87 \\
Jujuy & 19,99 & 19,83 & 16,40 & 12,85 & 9,86 & 12,55 & 11,53 & 7,18 & 7,61 & 6,05 \\
La Rioja & 2,76 & 6,80 & 10,31 & 11,08 & 2,52 & 9,55 & 10,77 & 7,40 & 7,81 & 9,66 \\
Salta & 40,73 & 36,60 & 39,07 & 35,06 & 27,96 & 30,66 & 31,20 & 24,48 & 23,55 & 26,32 \\
Santiago del Estero & 5,73 & 3,55 & 3,83 & 5,94 & 12,29 & 14,70 & 10,39 & 8,57 & 5,77 & 3,86 \\
Tucumán & 29,35 & 30,99 & 28,66 & 33,44 & 35,67 & 30,61 & 29,17 & 22,98 & 21,73 & 26,25
\end{tabular}

Fuente: Elaboración personal sobre la base de CONSEJO FEDERAL DE INVERSIONES. (2001).

ESTUDIOS GEOGR., LXVI, 259, JULIO-DICIEMBRE, 533-556, 2005. ISSN: 0014-1496 
CuAdro 3. "EXPortaciones Provinciales, SEGún categorías productivas

SELECCIONADAS". REGIÓN DEL NOA

PERÍODO 1991-2000

\begin{tabular}{|c|c|c|c|c|c|c|c|c|c|c|}
\hline Región del NOA & 1991 & 1992 & 1993 & 1994 & 1995 & 1996 & 1997 & 1998 & 1999 & 2000 \\
\hline Productos primarios & 63,00 & 67,00 & 66,00 & 68,00 & 65,00 & 68,00 & 72,00 & 75,00 & 77,00 & 72,00 \\
\hline Agroindustria & 20,00 & 18,00 & 13,00 & 11,00 & 13,00 & 15,00 & 13,00 & 12,00 & 11,00 & 14,00 \\
\hline Industria automotriz & 5,66 & 5,87 & 8,95 & 8,62 & 8,77 & 4,61 & 3,28 & 3,79 & 3,19 & 5,31 \\
\hline Catamarca & 1991 & 1992 & 1993 & 1994 & 1995 & 1996 & 1997 & 1998 & 1999 & 2000 \\
\hline Productos primarios & 84,56 & 92,72 & 77,74 & 93,64 & 73,99 & 54,68 & 89,15 & 97,22 & 97,05 & 96,12 \\
\hline Agroindustria & 11,14 & 2,49 & 5,89 & 0,27 & 0,11 & 14,85 & 3,27 & 1,91 & 1,52 & 1,65 \\
\hline Industria automotriz & 0,00 & 0,00 & 0,00 & 0,00 & 0,00 & 0,00 & 0,00 & 0,00 & 0,00 & 0,00 \\
\hline Jujuy & 1991 & 1992 & 1993 & 1994 & 1995 & 1996 & 1997 & 1998 & 1999 & 2000 \\
\hline Productos primarios & 68,05 & 72,92 & 71,88 & 73,69 & 73,37 & 79,01 & 81,23 & 84,17 & 82,74 & 71,09 \\
\hline Agroindustria & 23,50 & 20,73 & 17,09 & 10,73 & 16,80 & 15,73 & 13,57 & 12,49 & 13,12 & 21,73 \\
\hline Industria automotriz & 0,00 & 0,00 & 0,00 & 0,00 & 0,00 & 0,00 & 0,00 & 0,00 & 0,00 & 0,00 \\
\hline La Rioja & 1991 & 1992 & 1993 & 1994 & 1995 & 1996 & 1997 & 1998 & 1999 & 2000 \\
\hline Productos primarios & 13,44 & 78,08 & 81,70 & 74,92 & 71,35 & 57,02 & 63,41 & 26,57 & 31,39 & 48,72 \\
\hline Agroindustria & 61,41 & 18,77 & 16,46 & 15,51 & 12,96 & 23,64 & 17,61 & 43,75 & 39,85 & 33,49 \\
\hline Industria automotriz & 0,00 & 0,00 & 0,00 & 0,00 & 0,00 & 0,00 & 0,00 & 0,00 & 0,00 & 0,00 \\
\hline Salta & 1991 & 1992 & 1993 & 1994 & 1995 & 1996 & 1997 & 1998 & 1999 & 2000 \\
\hline Productos primarios & 89,29 & 95,83 & 94,81 & 94,40 & 94,95 & 94,79 & 96,76 & 94,37 & 95,73 & 94,44 \\
\hline Agroindustria & 2,72 & 3,74 & 1,67 & 1,68 & 2,53 & 2,17 & 0,94 & 3,03 & 1,88 & 3,00 \\
\hline Industria automotriz & 0,00 & 0,00 & 0,00 & 0,00 & 0,00 & 0,00 & 0,00 & 0,00 & 0,00 & 0,00 \\
\hline Santiago del Estero & 1991 & 1992 & 1993 & 1994 & 1995 & 1996 & 1997 & 1998 & 1999 & 2000 \\
\hline Productos primarios & 83,26 & 93,85 & 86,94 & 92,78 & 98,75 & 93,38 & 98,46 & 97,63 & 98,03 & 96,25 \\
\hline Agroindustria & 10,21 & 0,24 & 0,06 & 0,19 & 0,06 & 0,00 & 0,02 & 0,99 & 1,72 & 2,11 \\
\hline Industria automotriz & 0,00 & 0,00 & 0,00 & 0,00 & 0,00 & 0,00 & 0,00 & 0,00 & 0,00 & 0,00 \\
\hline Tucumán & 1991 & 1992 & 1993 & 1994 & 1995 & 1996 & 1997 & 1998 & 1999 & 2000 \\
\hline Productos primarios & 24,85 & 24,79 & 17,77 & 32,84 & 25,44 & 29,98 & 31,67 & 32,97 & 37,18 & 30,66 \\
\hline Agroindustria & 35,20 & 34,48 & 23,25 & 19,83 & 23,25 & 31,37 & 28,95 & 27,71 & 24,88 & 29,05 \\
\hline Industria automotriz & 19,30 & 18,90 & 31,05 & 25,71 & 24,54 & 14,78 & 10,88 & 15,76 & 14,35 & 20,15 \\
\hline
\end{tabular}

Fuente: Elaboración personal sobre la base de CONSEJO FEDERAL DE INVERSIONES. (2001).

\section{Resumen}

En este trabajo nos proponemos estudiar el proceso de diferenciación regional en la Argentina durante la última década, sobre la base de los conceptos de mercado mundial, región y división territorial del trabajo. Nuestra investigación se circunscribe a la región del Noroeste Argentino, constituida por las provincias de Catamarca, Jujuy, La Rioja, Santiago del Estero, Salta y Tucumán. De este modo, intentaremos explicar sus elevadas y persistentes tasas de desempleo a través del análisis de la estructura productiva exportable regional, desagregada a escala provincial. La identificación de los nexos relacionales existentes entre el proceso de reestructuración económica, la composición de la estructura productiva exportable y la expulsión de fuerza de trabajo nos permitirá revelar las desigualdades intrarregionales existentes en el universo de análisis considerado.

Palabras clave: reestructuración productiva; desempleo; desigualdades regionales. 


\begin{abstract}
In this paper we approach to study the process of regional differentiation in the Argentina during the nineties, on the base of the world market, region and division of labour concepts. Our investigation is bounded to the region of the Argentinean Northwest, constituted by the counties of Catamarca, Jujuy, La Rioja, Santiago del Estero, Salta and Tucumán. This way, we will try to explain their high and persistent unemployment levels through the analysis of the regional exportable productive structure, carried to provincial level. The identification of relational nexuses between the economics restructuring process, composition of the exportable productive structure and the expulsion of labour force it will allow us to reveal the intraregional inequalities about the considered universe of analysis.
\end{abstract}

Keywords: productive restructuring; unemployment; regional inequalities.

\title{
Résumé
}

Dans ce papier nous approchons étudier le processus de différenciation régionale dans l'Argentine pendant les années quatre-vingt-dix, sur la base de le concept du système mondial, région et division du labour. Notre enquête est bornée à la région du Nord-ouest argentin, constituée par les comtés de Catamarca, Jujuy, La Rioja, Santiago del Estero, Salta et Tucumán. Ce chemin, nous essaierons d'expliquer leur haut et persistant taux de chômage à travers l'analyse de la structure productive exportable régionale, portée à niveau provincial. L'identification de liens relationnels entre le procesus de restructure économique, I'composition de la structure productive exportable et l'expulsion de force du labour il nous permettra de donner billet des inégalités inter-régionnal existantes dans l'univers d'analyse considéré.

Mots-clé: restructure économique; chômage; inégalités régionnal. 